\title{
A SIMPLIFIED CALCULATION METHOD FOR SYMMETRICAL LOADING OF A SINGLE-SPAN COMPOSITE STRING STEEL STRUCTURE
}

\author{
Edmundas BEIVYDAS* \\ Vilnius Gediminas Technical University, Vilnius, Lithuania
}

Received 14 July 2019; accepted 8 October 2019

\begin{abstract}
The article presents single-span composite string steel structure. The article discusses the calculation method for the single-span composite string structure when the load is symmetrical, while the string and bottom cable act as absolutely flexible elements. It presents the way the displacements and the shear force in the supports are calculated for the distributed and concentrated loads. Calculations with a pre-tensioned string are provided. The results are compared with the results obtained with the finite element method program. The conclusions present the results obtained.
\end{abstract}

Keywords: bridge, symmetrical load, suspended cable, string, nonlinear analysis, hanging road, displacements, innovate structure.

\section{Introduction}

Suspended constructions are some of the most impressive and largest cross-over structures in the world (Gimsing, 1997; Kulbach, 1999). Such designs are effective because most of the elements are stretched which leads to the lowest steel costs. One of the most rational constructions is a single-span design (Strasky, 2005), however, this design is more commonly used for pedestrian bridges and its outline is not suitable for other transport.

In order to produce the most efficient construction, cable-supported structure can be combined (Sandovič \& Juozapaitis, 2012; Chen, Cao, Chu, Hu, \& Li, 2014) with a string (Yunitskiy, 2006), (Figure 1). In addition to reducing the kinematic displacements in the structure when the load is asymmetrical, the string would also form a straight line for the transport movement (Yunitskiy, 2019; Linkute, 2015). In such manner the traffic of this type could be used not only for pedestrians but also for other types of transport, such as cars, trains and etc. Moreover, the construction can also be used for overlapping large span roof structures.

The main parameters of the combined string system (Figure 2) comprises the lower cable sag, the lower cable and string axial rigidity ratios and the pre-tensioning force of the string. The outline of the lower cable forms a parabola (Beivydas, 2018). Such constructions are very complex, therefore, to facilitate their design the article below provides a simplified engineering methodology for this design with symmetrical load where the string and the bottom cable represent absolutely flexible elements.

In the calculation of the displacements and stresses of the combined string structure the behaviour of the structure depends not only on the loading location, but also on the method of loading. Thus, two cases will be analysed: when the structure is loaded with columns (Figure 3) and when the structure is loaded with a distributed load (Figure 6).
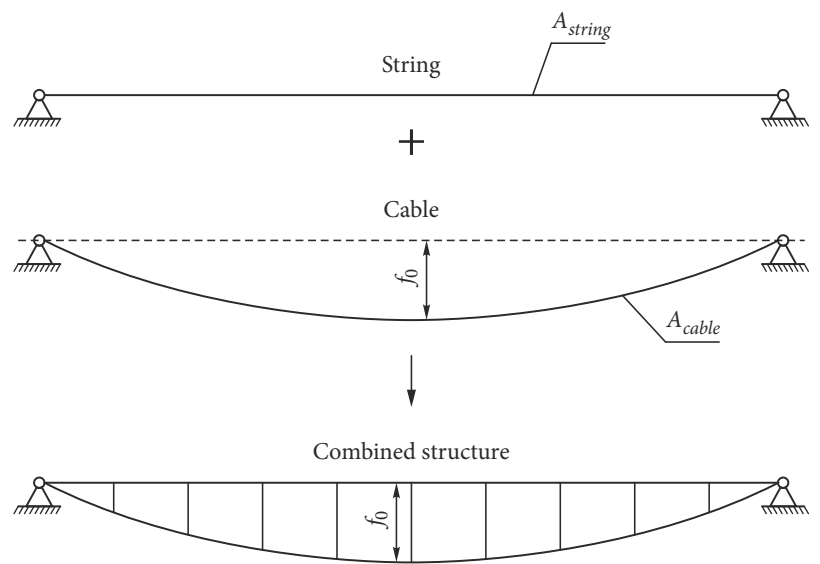

Figure 1. Combined string structure composing

*Corresponding author. E-mail: edmundas.beivydas@vgtu.lt 


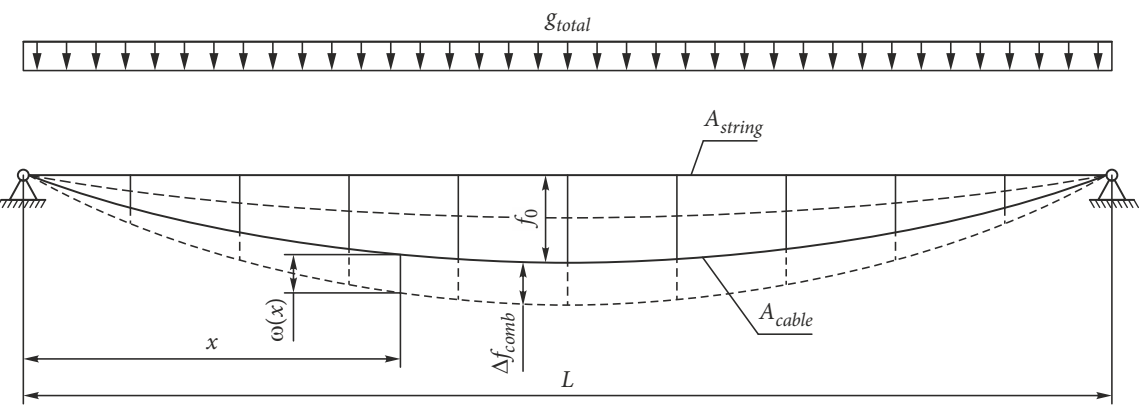

Figure 2. Combined string structure scheme

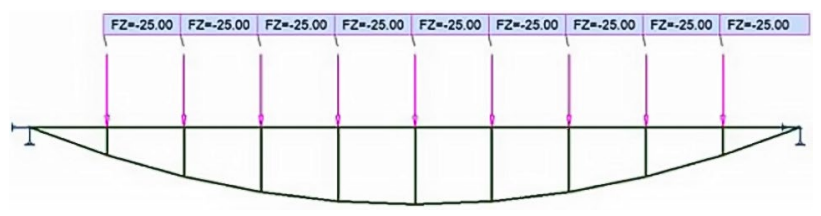

Figure 3. Load diagram when the load is transmitted through the struts

When load is transferred via the struts the construction should include cross beams. Such a case may be applied to the bridge deck by supporting the cross beams. In the case of the second load (Figure 6), the load is transferred via the string. This case can be applied to innovative structures such as hanging roads or bridges, when the string is used as a rail, etc. This case can also be used for bridge or roof deck support on strings.

\section{The calculation of displacements and stresses}

The main task of calculating the combined string structure is to calculate the load taken by the upper element (the string) and the load taken by the lower element (the cable).

The equations for calculating the displacement of strings and the suspended cable as separate elements have already been identified (Schlaich, Bogle, \& Bleicher, 2011; Chen et al., 2014; Kmet \& Kokorudova, 2009; Greco, Impollonia, \& Cuomo, 2014):

$$
\Delta f_{\text {string }}=\sqrt[3]{\frac{3 \cdot g_{\text {string }} \cdot L^{4}}{64 \cdot E_{\text {string }} \cdot A_{\text {string }}}}
$$

where:

$\Delta f_{\text {string }}$ - string displacement in the middle of span;

$g_{\text {string }}$ - Load taken over by a string;

$L$ - the lenght of construction span;

$E_{\text {string }}$ - Elasticity module of the string;

$A_{\text {string }}$ - Area of the string.

$$
\Delta f_{\text {cable }} \cong \frac{3}{128} \cdot \frac{g_{\text {cable }} \cdot L^{4}}{E_{\text {cable }} \cdot A_{\text {cable }} \cdot f_{0}^{2}},
$$

where:

$\Delta f_{\text {cable }}$ - cable displacement in the middle of span;

$g_{\text {cable }}$ - Load taken over by a bottom cable;
$E_{\text {cable }}$ - cable elasticity module;

$A_{\text {cable }}$ - Area of the cable;

$f_{0}$ - initial sag of cable.

The following assumptions are taken into account when calculating the displacments and the stresses of combined string structure:

1. The columns between the cable and the strings do not get deformed;

2. The string and the cable are absolutely flexible elements;

3. The string and cable displacements in the columns are equal;

4. Bottom cable outline - parabolic;

5. The columns are placed so densely that a split load is assumed to be transmitted to the lower cable.

By knowing the equations of the displacements of the strings' (1) and the cable (2) we can easily calculate the displacements of the combined design. The resulting equation of the displacement of the strings and the cable is:

$$
\sqrt[3]{\frac{3 \cdot g_{\text {string }} \cdot L^{4}}{64 \cdot E_{\text {string }} \cdot A_{\text {string }}}}=\frac{3}{128} \cdot \frac{g_{\text {cable }} \cdot L^{4}}{E_{\text {cable }} \cdot A_{\text {cable }} \cdot f_{0}^{2}} .
$$

In the equation we have two unknown variables - the load taken by the cable and the load taken by the strings. With the knowledge that the string and cable take on different loads, we can come up with the following conclusion when loading a combined structure:

$$
g_{\text {total }}=g_{\text {string }}+g_{\text {cable }} \text {, }
$$

where:

$g_{\text {total }}$ - external load.

Bearing this assumption in mind (4), we can make the following change:

$$
g_{\text {string }}=g_{\text {total }}-g_{\text {cable }} \text {. }
$$

After introducing the changes, solving and organizing the equation, we can get the load taken by the bottom cable:

$$
\begin{aligned}
& g_{\text {cable }}=\sqrt[3]{\sqrt{\frac{1}{27} \cdot C^{3}+\frac{1}{4} \cdot D^{2}}-\frac{1}{2} \cdot D}+ \\
& \sqrt[3]{-\sqrt{\frac{1}{27} \cdot C^{3}+\frac{1}{4} \cdot D^{2}}-\frac{1}{2} \cdot D}
\end{aligned}
$$


where:

$$
\begin{aligned}
& C=\frac{32768}{9} \cdot \frac{E_{\text {cable }}^{3} \cdot A_{\text {cable }}^{3} \cdot f_{0}^{6}}{E_{\text {string }} \cdot A_{\text {string }} \cdot L^{8}} ; \\
& D=g_{\text {sum }} \cdot \frac{32768}{9} \cdot \frac{E_{\text {cable }}^{3} \cdot A_{\text {cable }}^{3} \cdot f_{0}^{6}}{E_{\text {string }} \cdot A_{\text {string }} \cdot L^{8}} .
\end{aligned}
$$

Once the solutions are received into the equations that have already been known, we obtain the following result:

$$
\Delta f_{\text {comb }} \cong \frac{3}{128} \cdot \frac{L^{4}}{E_{\text {cable }} \cdot A_{\text {cable }} \cdot f_{0}^{2}} \cdot g_{\text {cable }} \text {. }
$$

In general we obtain this equation of displacements:

$$
\omega(x)=\Delta f_{\text {comb }} \cdot \frac{L}{4} \cdot x-4 \cdot \frac{\Delta f_{\text {comb }}}{L^{2}} \cdot x^{2},
$$

where:

$\Delta f_{\text {comb }}$ - combined construction displacement in the middle of span;

$\omega(x)$ - combined construction displacement;

$x$ - horizontal distance from the edge support to the counting point.

\section{The case when the load is transferred to the struts}

In this particular case the equation of the displacement calculation is the following (7). The shear forces in the supports are calculated using the known equation $(9,10)$ (Schleich et al., 2011) applying the superposition principle (8):

$$
H_{\text {total }}=H_{\text {string }}+H_{\text {cable }} \text {. }
$$

By using the known equation we get:

$$
\begin{aligned}
& H_{\text {string }}=\frac{g_{\text {string }} \cdot L^{2}}{8\left(\Delta f_{\text {string }}\right)} ; \\
& H_{\text {cable }}=\frac{g_{\text {cable }} \cdot L^{2}}{8\left(\Delta f_{\text {string }}\right)},
\end{aligned}
$$

where:

$H_{\text {total }}$ - combined construction shear force;

$H_{\text {string }}$ - string shear force;

$H_{\text {cable }}$ - cable shear force.

Numerical analysis was performed using Autodesk Robot Structural analysis software.

Modeled structure with a span of $50 \mathrm{~m}$. Initial sag of bottom cable is $5 \mathrm{~m}$. The distance between the struts is $5 \mathrm{~m}$. The string and cable are modeled as cable elements. Nonlinear analysis was used to calculate the structure. The displacement and axial force diagrams we can see in Figure 4.

Numerical results compared with analytical ones. (Figures 5,6$)$. I = $A_{\text {string }} / A_{\text {cable }}$.

We can see that the numerical and analytical results are very similar. The differences from $8 \%$ to $10 \%$ were calculated for the displacements. The differences are to $1 \%$ were calculated for the shear forces. There is a case where the initial sag of the lower cable is L / 10 because the greatest differences are obtained in this case. a)

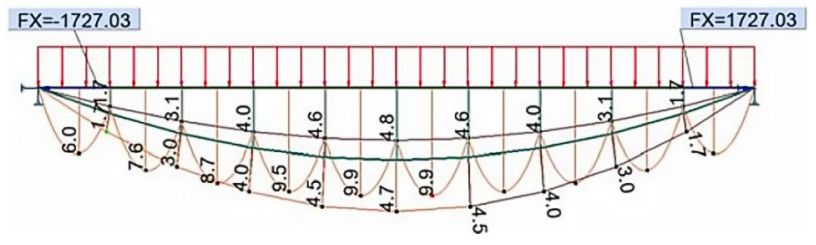

b)

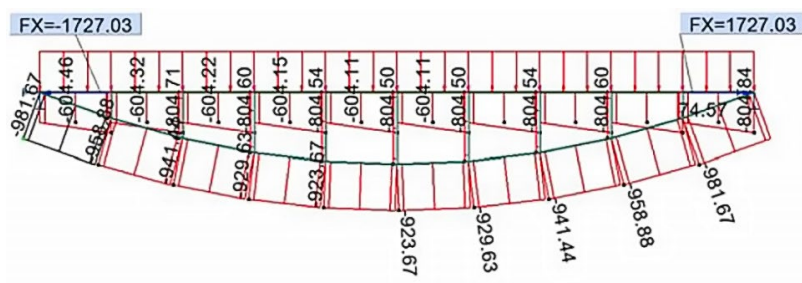

Figure 4. Diagrams from Autodesk Robot Structural analysis: a) Displacements diagram b) Axial forces diagram

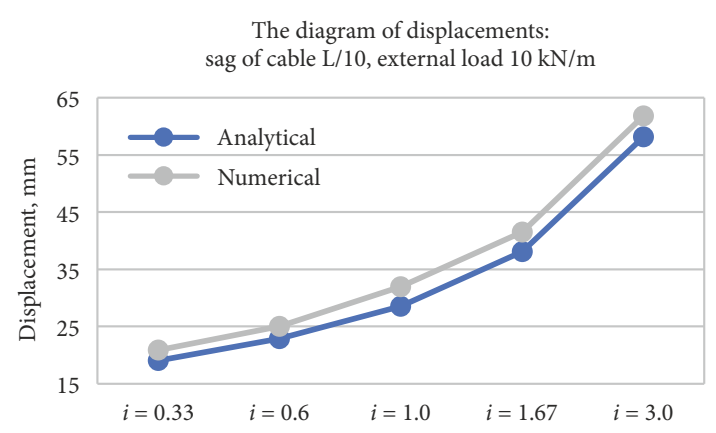

Figure 5. The diagram of displacements, in case the load is transferred to the columns, the string is not pre-tensioned

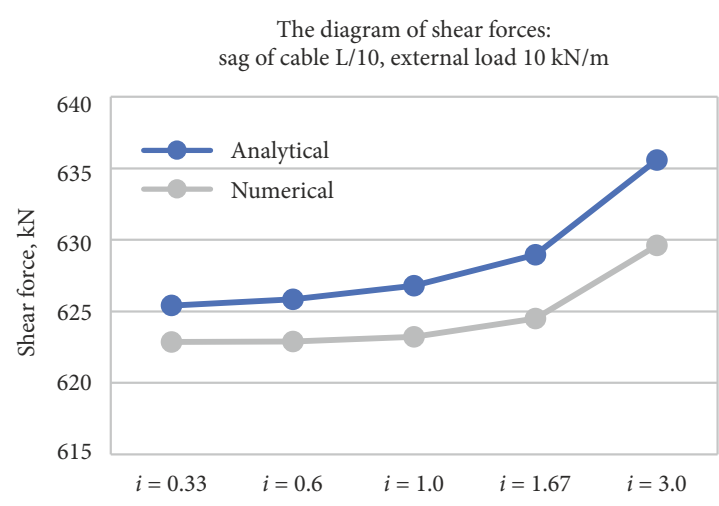

Figure 6. The diagram of shear forces, in case the load is transferred to the struts, the string is not pre-tensioned

\section{The case when the load is distributed}

In case of the distributed load (Figure 7) all calculations are made in a similar manner, as in the case when the loads are transmitted through the columns. In this case additional local displacements (Figure 7) occur which cause additional stress.

The calculations of the local displacements of the strings and the resulting shear forces do not estimate that the columns are shifted unevenly. 


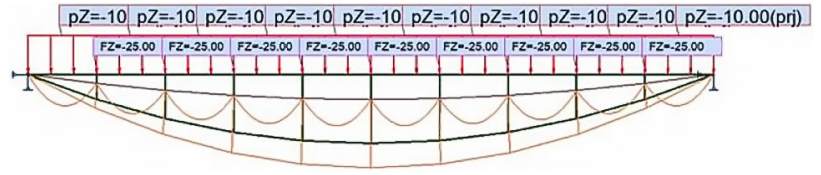

Figure 7. The case when the load is distributed

$$
\begin{aligned}
& H_{\text {string, local }}=\sqrt[3]{\frac{1}{24} \cdot\left[g_{\text {total }} 2 \cdot\left(\frac{L}{n+1}\right)^{2} \cdot E_{\text {string }} \cdot A_{\text {string }}\right]} \\
& \Delta f_{\text {string, local }}=\sqrt[3]{\frac{3}{64} \cdot \frac{g_{\text {total }}\left(\frac{L}{n+1}\right)^{4}}{E_{\text {string }} A_{\text {string }}}}
\end{aligned}
$$

where:

$H_{\text {string,loal }}$ - the shear force in the supports is caused by local displacements;

$\Delta f_{\text {string,loal }}$ - local string displacement;

$n$ - number of columns.

The principle of superposition is applied in calculating the total shear force:

$$
H_{\text {total }}=H_{\text {string }}+H_{\text {cable }}+H_{\text {string,loal }}
$$

Therefore, these are the equations for the displacements $(7,12)$ and the stresses $(11,13)$ when the load is distributed.

Numerical results were obtained using a finite element calculation program. The numerical and analytical results are very similar (Figure 8 ). The differences from $9 \%$ to $10 \%$ percent were calculated for the displacements. The differences are to $1 \%$ were estimated by calculating the shear forces.

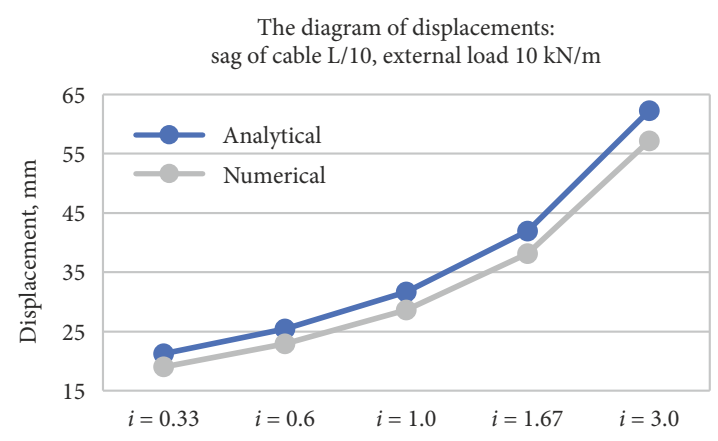

Figure 8 . The diagram of displacements, when the load is distributed, the string is not pre-tensioned

\section{Conclusions}

First, the combined structure are constructed, then the basic parameters are selected for the design. By means of the familiar solutions a simplified calculation of displacement and stress of the construction is provided when the load is symmetrical.
Calculations are provided for two load cases: when the load is applied by using cross beams and when the load is transmitted directly to the string. The versions of construction are presented for each load case, for example, a hanging road or bridge with a deck and without a deck.

Calculations are compared to the results obtained by using the numerical method. The numerical and analytical results are very similar. The differences from $8 \%$ to $10 \%$ were calculated for the displacements. The differences are to $1 \%$ were obtained by calculating the shear forces.

When variable load is transmitted through the string, the displacements remain the same as in the first case, however, the shear forces differ. We can see this by comparing equations 8 and 13 .

\section{References}

Beivydas, E. (2018). Vieno tarpatramio kabamosios kombinuotos styginès konstrukijos skaitinè analizè. Mokslas - Lietuvos ateitis - Science - Future of Lithuania, 10, 1-5.

https://doi.org/10.3846/mla.2018.2867

Chen, Z., Cao, H., Zhu, H., Hu, J., \& Li, S. (2014). A simplified structural mechanics model for cable-truss footbridges and its implications for preliminary design. Engineering Structures, 68, 121-133. https://doi.org/10.1016/j.engstruct.2014.02.015

Gimsing, N. J. (1997). Cable supported bridges: concept and design (2nd ed.). Chichester: John Wiley \& Sons.

Greco, L., Impollonia, N., \& Cuomo, M. (2014). A procedure for the static analysis of cable structures following elastic catenary theory. International Journal of Solids and Structures, 51, 1521-1533. https://doi.org/10.1016/j.ijsolstr.2014.01.001

Kmet, S., \& Kokorudova, Z. (2009). Non-linear closed form computational model of cable trusses. International Journal of Non-linear Mechanics 44, 735-744.

https://doi.org/10.1016/j.ijnonlinmec.2009.03.004

Kulbach, V. (1999). Half-span loading of cable structures. Journal of Constructional Steel Research, 49(2), 167-180. https://doi.org/10.1016/S0143-974X(98)00215-6

Linkutè, E. (2015). Iš anksto ịtemptų styginiu plieno tiltų komponavimas ir elgsenos analize (magistro darbas). Vilniaus Gedimino technikos universistetas, Vilnius.

Sandovič, G., \& Juozapaitis, A. (2012). The analysis of the behaviour of an innovative pedestrian steel bridge. In Procedia Engineering Steel Structures and Bridges 2012: 23rd Czech and Slovak International Conference (Vol. 40). Amsterdam: Elsevier Science Ltd. https://doi.org/10.1016/j.proeng.2012.07.117

Schlaich, M., Bogle, A., \& Bleicher, A. (2011). Entwerfen und Konstruieren Massivbau. Institut fur Bauingenieurwesen Technische universitat Berlin.

Strasky, J. (2005). Stress-ribbon and supported cable pedestrian bridges. London: Thomas Telford Ltd. https://doi.org/10.1680/sracspb.32828

Yunitskiy, A. (2006). String Transport in questions and answers. Moscow, Russia.

Yunitskiy, A. E. (2019). Strunnye transportnye sistemy: na Zemle $i v$ Kosmose. Silakrogs: PNB print. 